\title{
WEDGE ARTHRODESIS OF THE WRIST
}

\author{
David L. Evans, London, England
}

From the Department of Orthopaedics, Westminster Hospital, London

The method of arthrodesis of the wrist here described was originally evolved by Mr E. P. Brockman in a case of severe flexion deformity of the wrist due to a long-standing Volkmann's ischaemic contracture. Subsequently the method was extended in its application to other cases of flexion deformity of the wrist and later was also used for arthrodesis of the wrist in cases without deformity.

Spike arthrodesis, devised and described by Higgs (1931), has now long been used in the operative treatment of hammer toe deformity. The spike of the proximal phalanx well inserted into the socket of the distal phalanx provides relatively large cancellous bone areas in intimate contact and good internal fixation. It is thus comparable to an impacted fracture and sound early union results. The arthrodesed toe is also shortened. In the arthrodesis of the wrist to be described, the lower end of the radius is shaped into a wedge and is then inserted into the carpus which has been split open like an oyster (Figs. 1 and 2). This arthrodesis is thus an extension of the spike arthrodesis adapted and modified to deal with a more complex joint. In addition to providing the pre-requisites for sound bony union, this

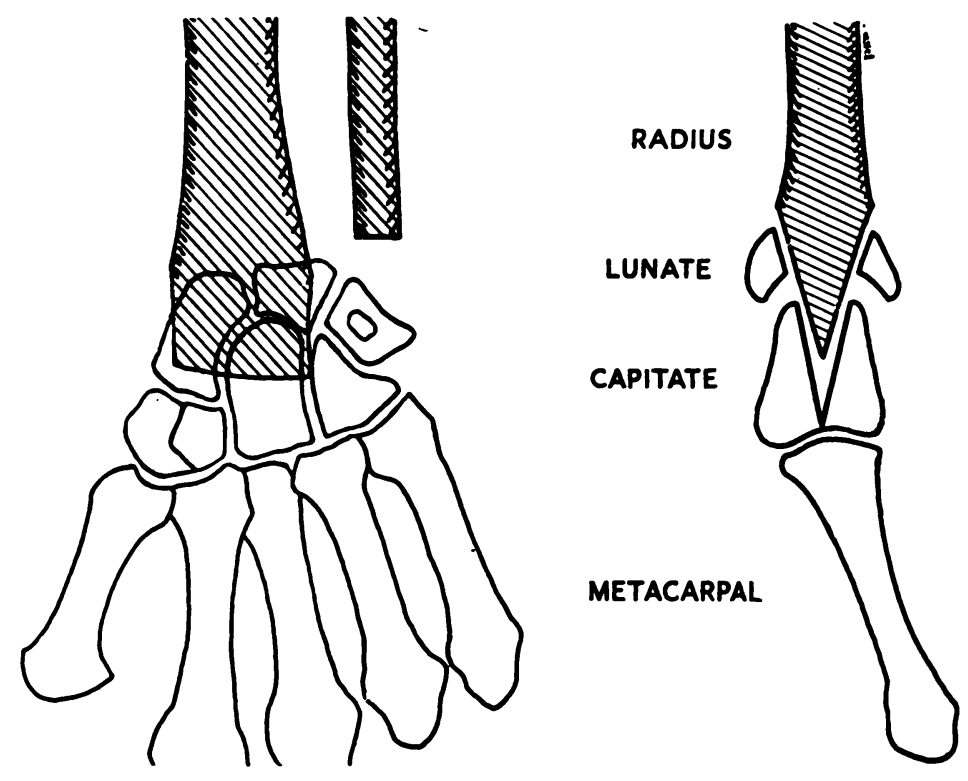

Fig. 1

Diagrams showing the position of the wedge in the split carpus.

arthrodesis similarly causes slight shortening of the forearm. The arthrodesis can be combined with resection of the lower end of the ulna when the return of rotation movements of the forearm is desired.

Of the many operations that have been described for obtaining wrist fusion, most have employed a dorsal approach and have included the use of a bone graft. The main variation in these techniques has been in the type of graft used. Thus onlay, inlay and sliding grafts, of compact or cancellous bone, from various sites and of varying shapes, have all been advocated (Abbott et al. 1942, Albee 1940, Brittain 1952, Colonna 1944, Butler 1949, Gill 1949, 
Thomas 1950). Smith-Petersen (1940), extending the operation of Darrach (1936) for excision of the lower end of the ulna, described a lateral approach to the wrist, which was exposed through the bed of the resected ulna, the excised portion of bone being used as an inlay graft.

The multiplicity of these operations suggests that none has been found completely satisfactory. Pseudarthrosis and fracture are complications of the use of any graft, and in a recent review of wrist fusions by various methods Ross (1950) reported that fracture of the graft was not infrequent, particularly after Brittain's method of arthrodesis.
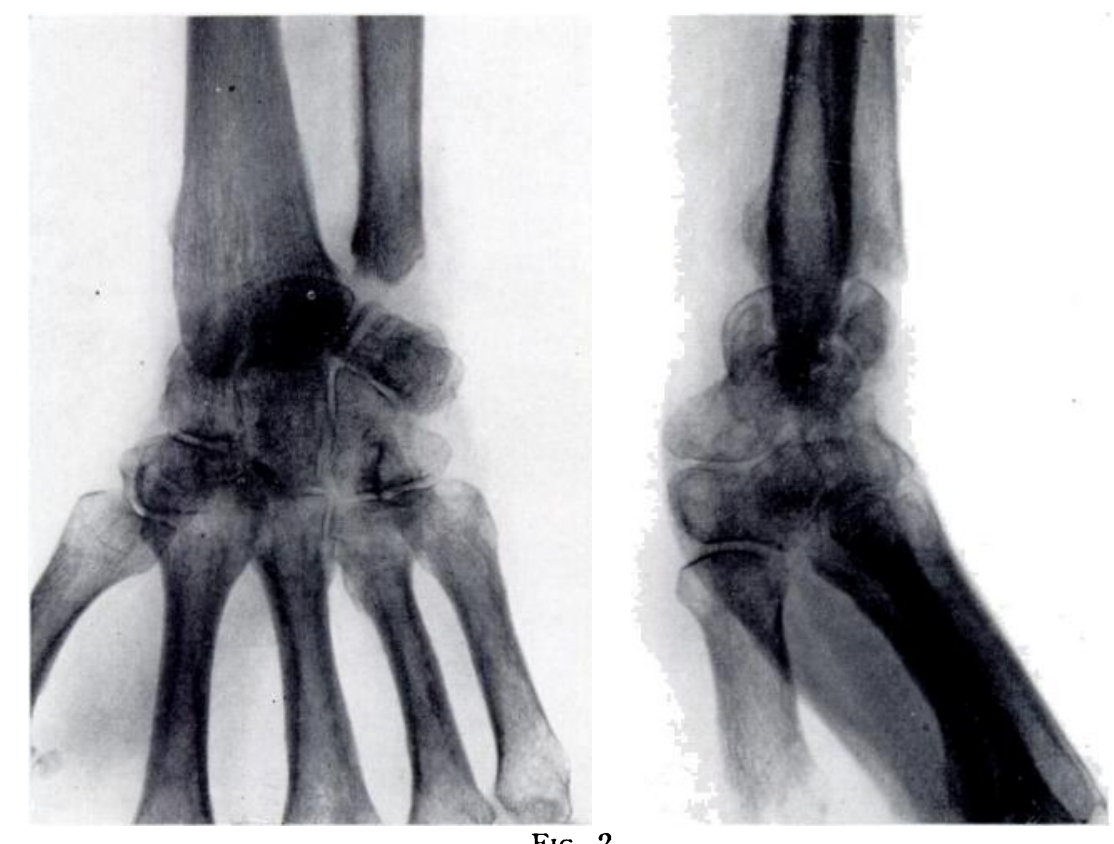

Post-operative radiographs.

Wedge arthrodesis eliminates the need for a graft; and when combined with resection of the lower end of the ulna to preserve full rotation at the superior radio-ulnar joint, it has proved a most satisfactory operation for routine wrist fusion. It appears to compare favourably with all other methods. Nissen (1951) strongly advocated its use, and briefly described the operation with minor technical differences.

\section{TECHNIQUE OF OPERATION}

A dry operative field can be maintained by the use of a pneumatic cuff applied to the upper arm. But this increases post-operative swelling, which has occasionally led to displacement of the wedge. It is therefore preferable not to use a pneumatic cuff. The amount of bleeding is small and easily controlled, and it does not interfere with the technique of the operation.

Through a four-inch longitudinal incision in the mid-line over the dorsum of the wrist, the extensor tendons are identified and retracted. The capsule of the wrist joint is divided transversely. (It is imperative not to open the back of the intercarpal joints by mistake, for the proximal row of the carpus then becomes impossible to control later in the operation.) The lower ends of the radius and ulna are delivered into the wound and the soft tissues stripped from their volar surfaces (Fig. 3). The wrist is now further flexed until the palm of the hand lies parallel to the forearm. If it is intended to preserve or attempt to increase the range of rotation of the forearm, the lower inch of the ulna is excised. If no rotation is expected or desired, the ulna is included in the forearm wedge.

vol. $37 \mathrm{~B}$, No. 1, FEBRUARY 1955 
With an osteotome, the radius is shaped into a wedge of dense cancellous bone, tapered to as fine a cutting edge as possible. The carpus is then divided transversely with an osteotome so that the two halves can be opened up like an oyster (Fig. 4). The cleft should extend well into the second row of the carpus and in particular into the capitate. It is at this stage that the importance of preserving the capsule and ligaments of the carpus is realised, for if these have been inadvertently damaged, the carpus tends to disintegrate and a firm fit of the wedge cannot be obtained. The wedge is now inserted into the carpus, using the osteotome as a guide, and pushed home. It should fit firmly into the cleft (Fig. 5). The retracted extensor tendons are released, a few anchoring sutures approximate the extensor retinaculum and subcutaneous tissues, and the skin is closed. With the wrist held in a neutral position between flexion and extension, an above-elbow padded plaster is applied and split dorsally to allow for subsequent swelling.

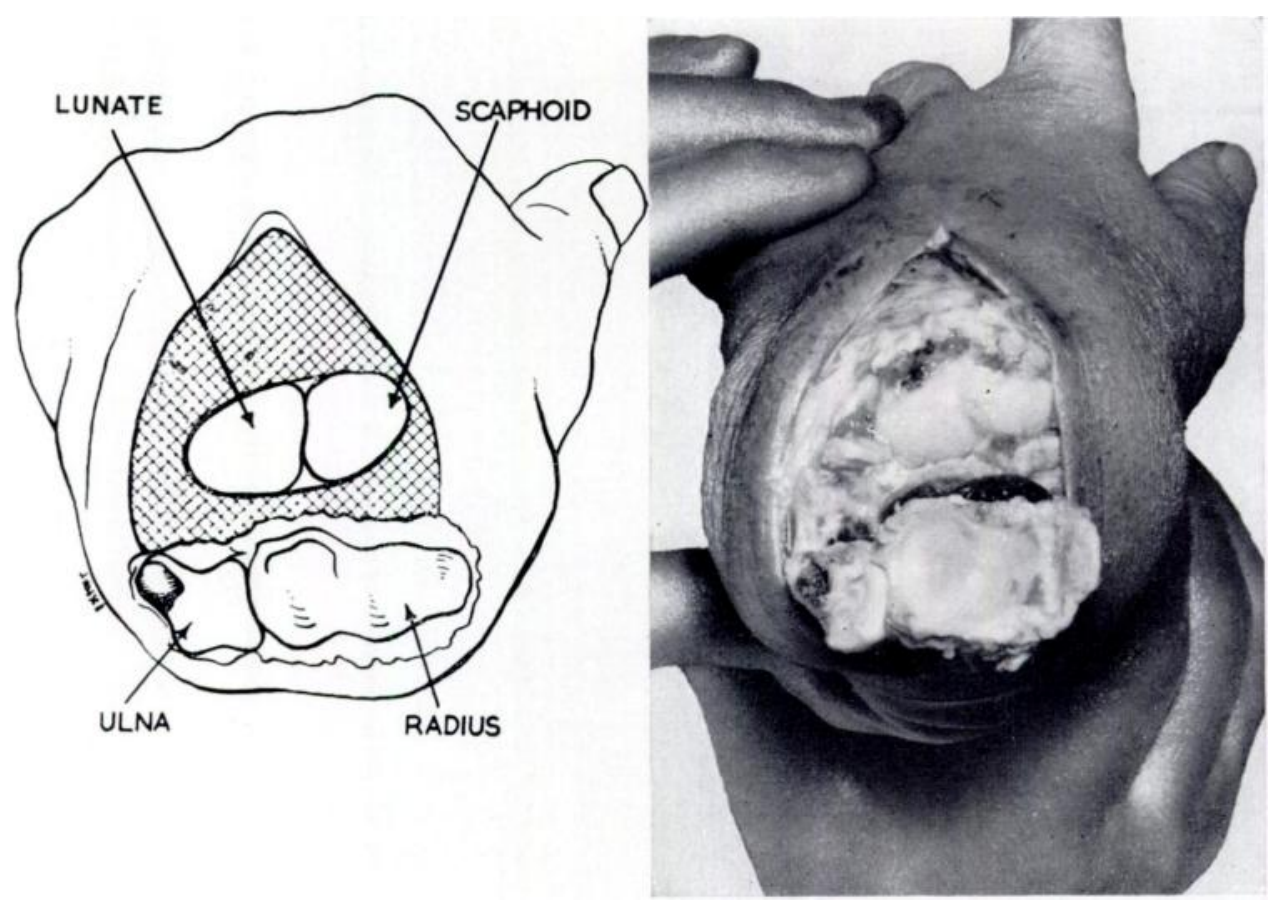

FIG. 3

The capsule of the radio-carpal joint has been divided transversely, and the wrist flexed through 180 degrees. Pronator quadratus can be seen stripped from the volar surface of the radius. In this case the ulnar styloid process has been avulsed by the medial ligament when the wrist was fully flexed.

Post-operative treatment-Elevation of the arm during the first few days assists in limiting the inevitable swelling of the hand and fingers. A radiograph is taken to confirm the position of the wedge in the carpus. Three weeks after operation the plaster is removed and the sutures are removed. A well moulded plaster is applied over stockinet and remains on for a total period of about three months, by which time union can be expected and further external support is seldom required.

\section{CLINICAL MATERIAL}

Eighteen patients in whom nineteen wrists had been arthrodesed by this method were available for review. Eight patients were male and ten were female. Their ages at operation varied from eight to fifty-five years. The length of follow-up varied from one to eighteeniyears. 


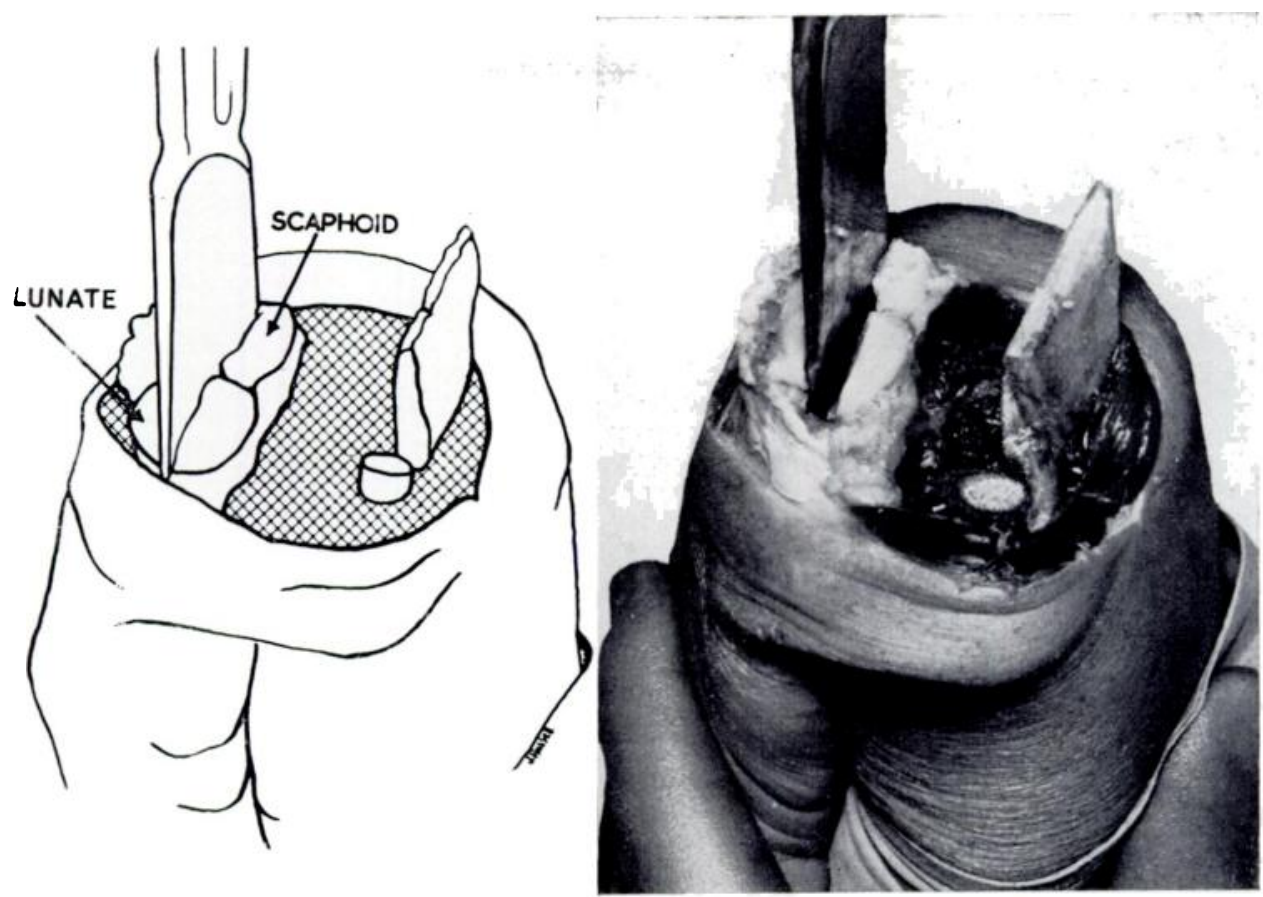

FIG. 4

The lower end of the radius has been tapered to a wedge and the distal inch of the ulna resected. The carpus is being split with an osteotome.

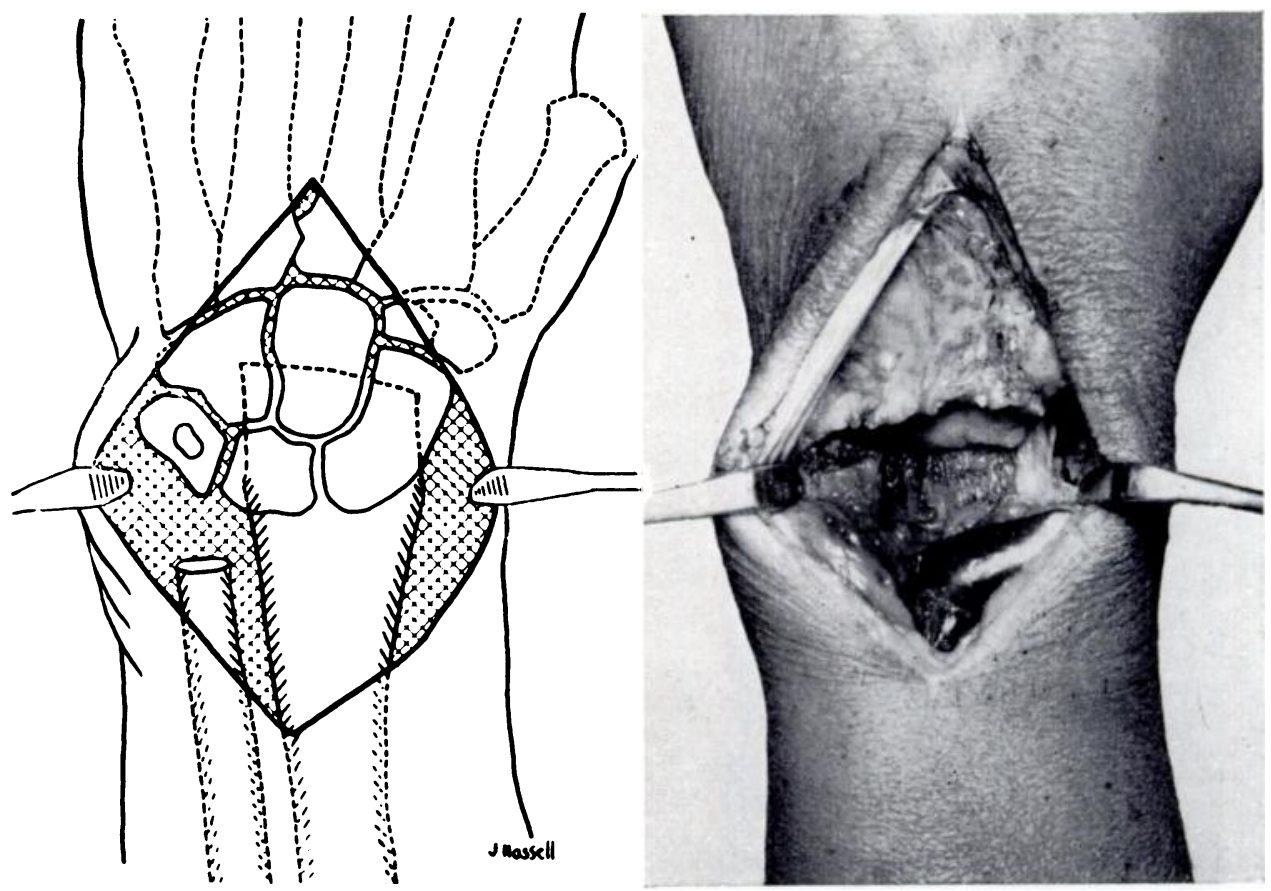

FIG. 5

The " wedge" has been inserted into the divided carpus, and fits securely. The resected lower end of ulna is seen.

VOL. 37 B, NO. 1, FEBRUARY 1955 
The cases fall into two main groups. In the first group of twelve, flexion deformity of the wrist was the essential problem (Table I). The causes were Volkmann's ischaemic contracture (two cases), spastic hemiplegia (seven cases), brachial plexus birth injury (one case), and

TABLE I

Analysis of Twelve Cases with Flexion Deformity of the Wrist

\begin{tabular}{|rr|c|c|c|}
\hline Case & Sex & Diagnosis & Age at operation & $\begin{array}{c}\text { Length of } \\
\text { follow-up } \\
\text { (years })\end{array}$ \\
\hline 1 & F. & Volkmann's ischaemic contracture & 14 & 18 \\
2 & M. & Volkmann's ischaemic contracture & 12 & 17 \\
3 & F. & Brachial plexus birth injury & 21 & 6 \\
4 & F. & Arthrogryposis multiplex congenita & 16 & 6 \\
5 & F. & Arthrogryposis multiplex congenita & $\begin{array}{r}\text { Left } 20 \\
\text { (re-operation 22) }\end{array}$ & 5 \\
6 & F. & Spastic hemiplegia & 19 & 10 \\
7 & F. & Spastic hemiplegia & 12 & 6 \\
8 & M. & Spastic hemiplegia & 19 & 4 \\
9 & M. & Spastic hemiplegia & 26 & 4 \\
10 & M. & Spastic hemiplegia & 17 & 4 \\
11 & M. & Spastic hemiplegia & 8 & 4 \\
12 & F. & Spastic hemiplegia & 17 & 3 \\
\hline
\end{tabular}

TABLE II

Analysis of Six Cases Without Flexion Deformity of the Wrist

\begin{tabular}{|c|c|c|c|c|}
\hline & & Diagnosis & $\begin{array}{c}\text { Age at } \\
\text { operation }\end{array}$ & $\begin{array}{c}\text { Length of } \\
\text { follow-up } \\
(\text { years })\end{array}$ \\
\hline 1 & M. & Fracture of scaphoid & 57 & 7 \\
2 & F. & Fracture lower end of radius & 45 & 6 \\
3 & F. & Kienböck's disease & 48 & 4 \\
4 & M. & Fracture of scaphoid & 55 & 2 \\
5 & M. & Fracture of scaphoid & 42 & 1 \\
\hline Chroumatic & arthritis & & 3 \\
\hline
\end{tabular}

arthrogryposis multiplex congenita (two cases-one bilateral). In the second group of six, pain with consequent loss of function was the essential problem (Table II). The causes were traumatic arthritis of the wrist (five cases) and chronic non-specific arthritis (one case). 


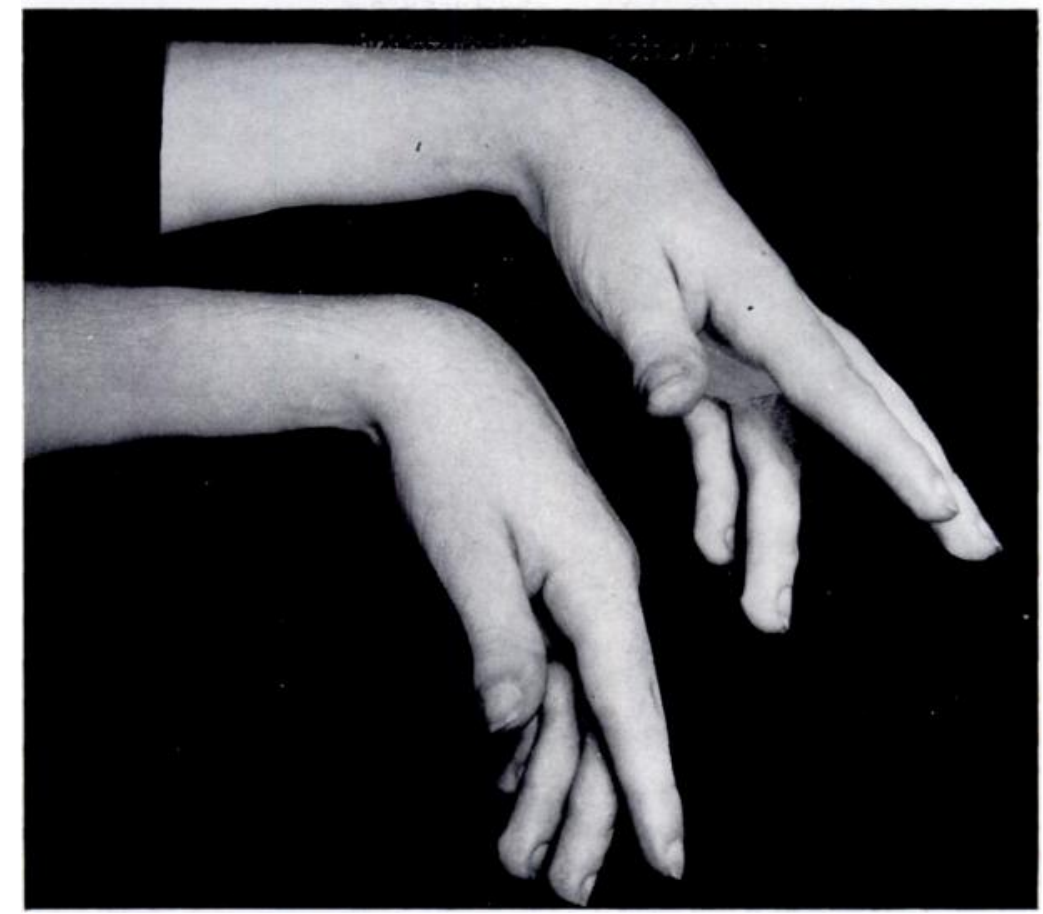

FIG. 6

Case 9-Congenital spastic hemiplegia, showing the appearance and function of the hand before operation.

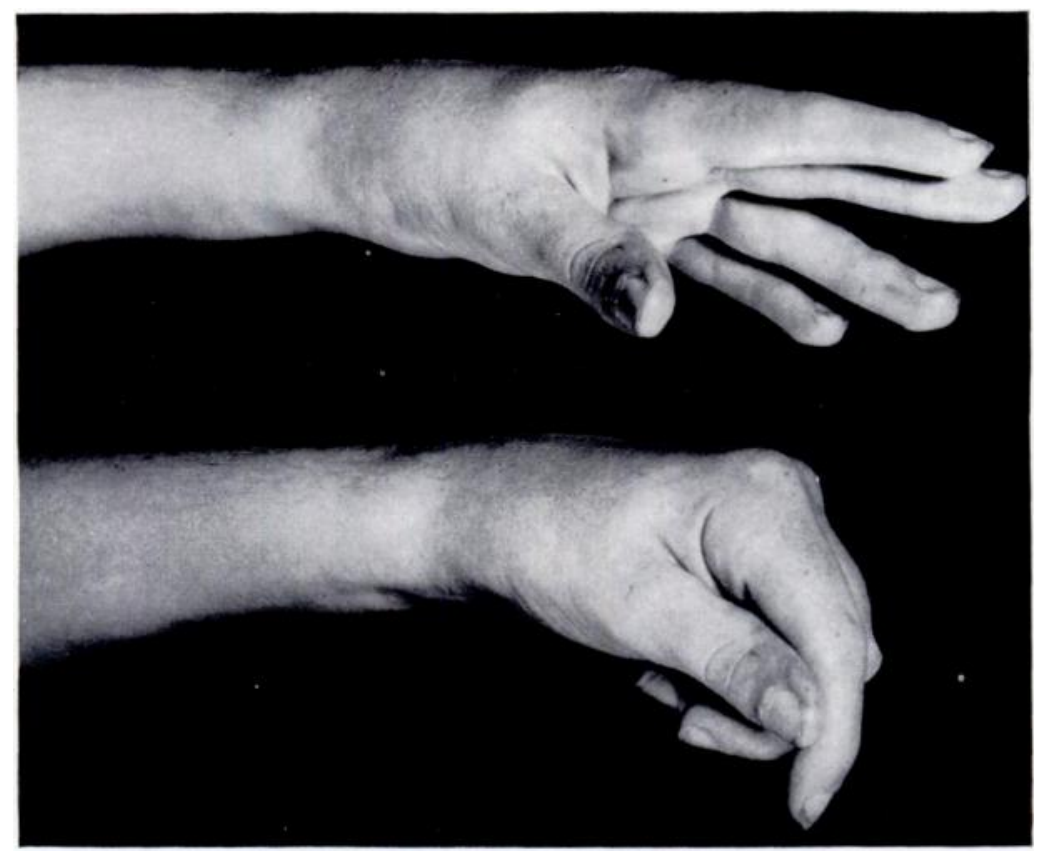

FIG. 7

Case 9-Condition after operation.

vol. 37 B, NO. 1, FEBRUARY 1955 


\section{RESULTS}

Cases with flexion deformity of the wrist-In all a sound fusion was obtained. The position of rotation of the forearm varied with the pre-existing deformity. Most wrists were arthrodesed in a pronated or semi-pronated position. The appearance of these hands was enormously improved and some improvement in function occurred in all (Figs. 6 and 7).

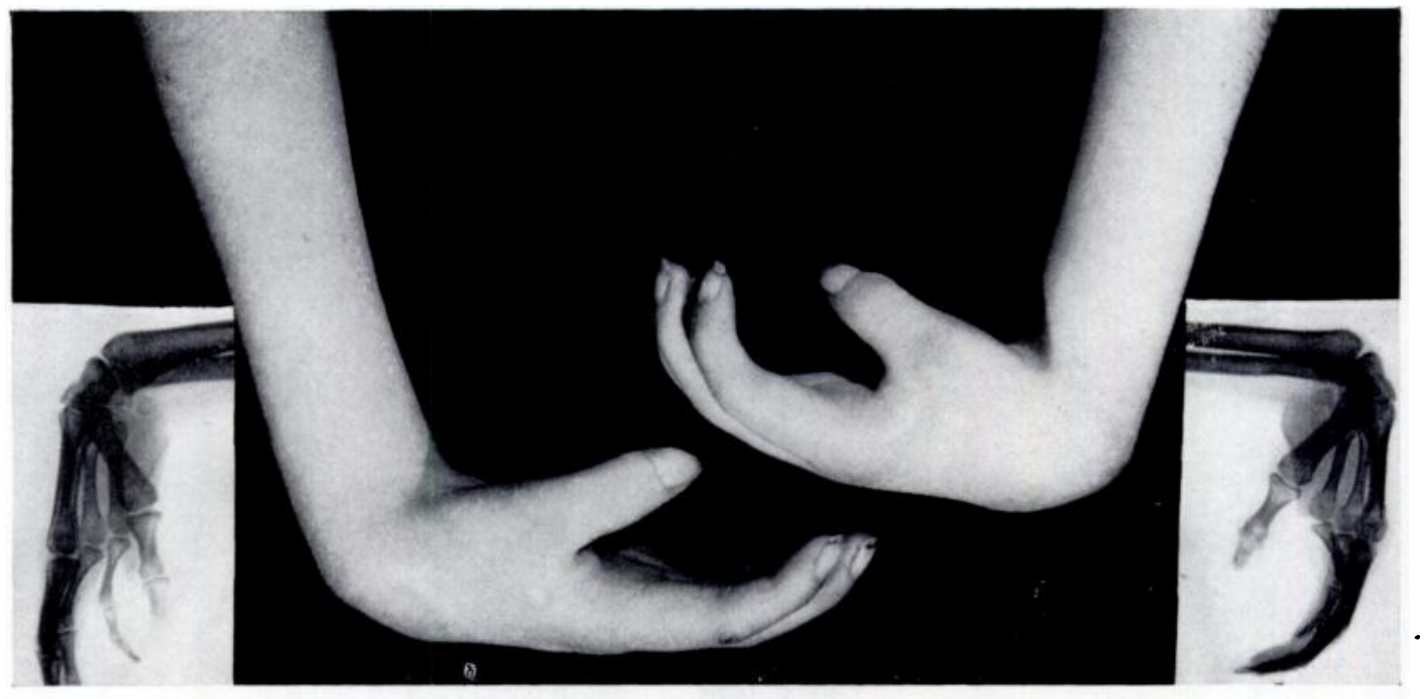

FIG. 8

Case 5-Arthrogryposis multiplex congenita, before operation.

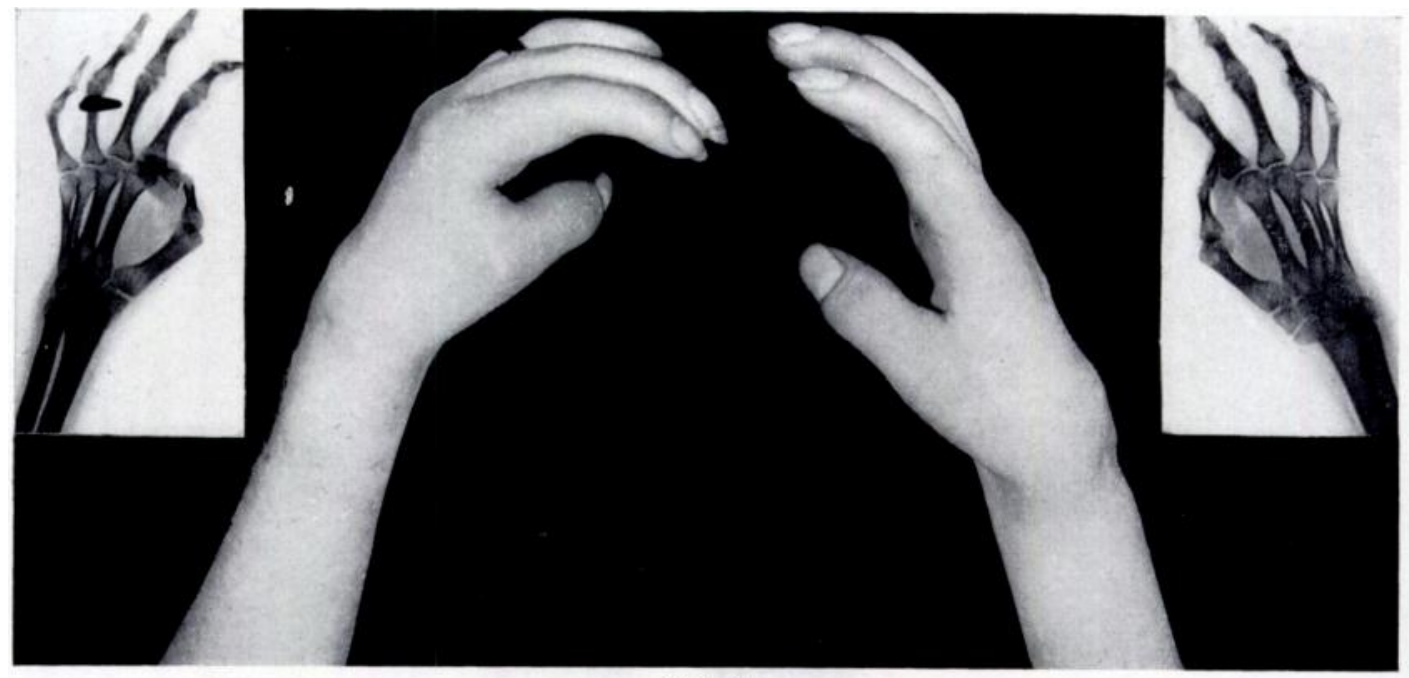

FIG. 9

Case 5 - Condition after operation.

In four cases resection of the lower end of the ulna had been performed, but in only one was rotation of the forearm increased.

In assessing the results of an operation of this kind the patient's views must be regarded as at least equal in importance to those of the surgeon. This is particularly true when the operation is undertaken primarily for the correction of an ugly deformity. All patients in this group were well pleased with the improvement in appearance of their hands, which was more important to them than the modest gain in function (Figs. 8 and 9). 
It is perhaps worth recording that three women (one with Volkmann's ischaemic contracture, one with spastic hemiplegia, and one with arthrogryposis multiplex congenita) were married after their operations. All were able to run their own homes and look after their families. One other woman, with spastic hemiplegia, subsequently obtained a better job as a result of her operation. One young man with Volkmann's ischaemic contracture felt able for the first time to enjoy playing team games, another with spastic hemiplegia took up ballroom dancing as a pastime, and a third, also with spastic hemiplegia, became engaged while in his plaster splint, married soon after it was removed, and was able later to obtain a better job. These personal testimonies reflect, far better than any figures can, the difference in these patients' outlook on life when an unsightly deformity was rendered less conspicuous.

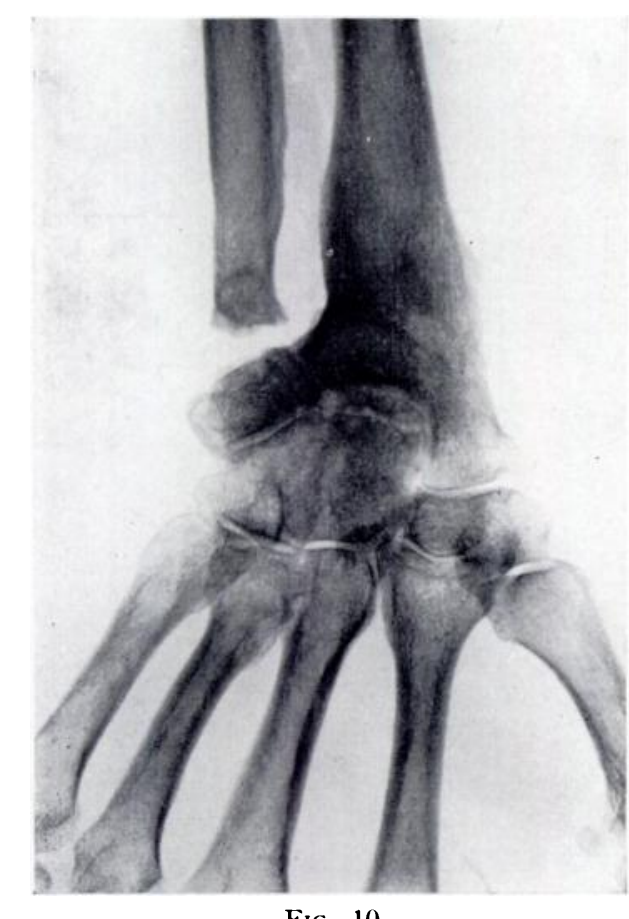

FIG. 10

Case 12-Radiograph nine years after operation. Fusion of radius with proximal row of carpal bones.

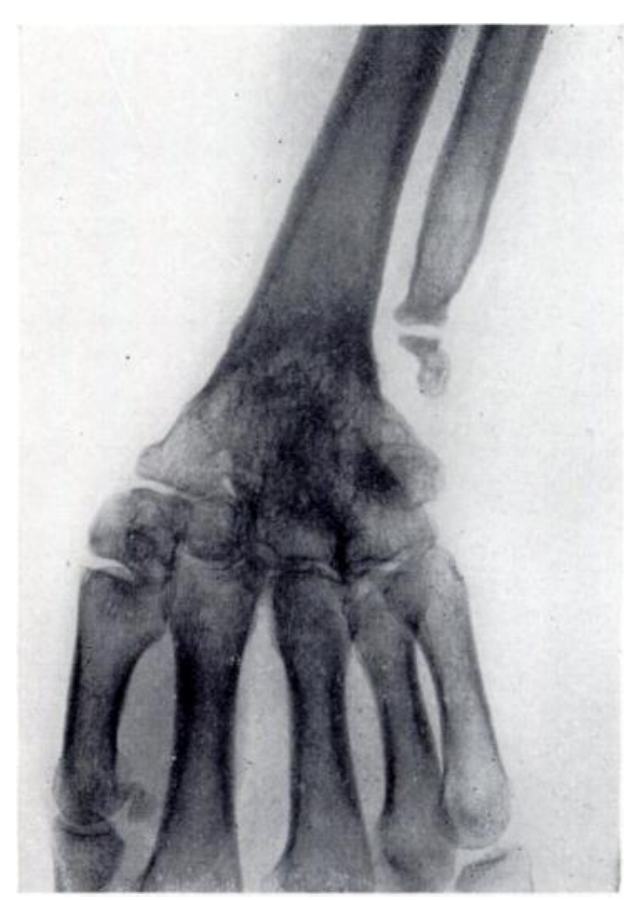

FIG. 11

Case 3-Radiograph four years after operation. Fusion of radius with both rows of carpal bones.

Cases without flexion deformity--Resection of the lower end of the ulna was performed in all these cases, and in all a sound arthrodesis was obtained with complete relief of pain. In five cases the functional result was excellent, full pronation and supination were preserved, and the patients were well satisfied with the result. In one case, though a sound fusion was gained, loss of function persisted; this patient suffered from post-encephalitic Parkinsonism, which probably accounted for the poor functional result.

Late radiographic appearances - In reviewing the late appearances of these arthrodeses, it was noted that in some cases fusion of the forearm wedge had occurred with only the proximal carpal row (Fig. 10), whereas in others there was sound fusion with both carpal rows (Fig. 11). Clinically these could not be distinguished.

Serial radiographs also showed well the remodelling that occurs at the site of arthrodesis. Though the original wedge of the radius remains visible for a year or longer, ultimately it becomes completely incorporated and indistinguishable in the new bone structure.

vOL. $37 \mathrm{~B}$, No. 1, FEBRCARY 1955 
Complications-Displacement of the wedge occurred in two cases. In both the arthrodesis had been performed for flexion deformity of the wrist. In one, the immediate cause was excessive post-operative swelling, which necessitated wide splitting of the plaster. The other occurred for no certain cause in the youngest patient in this series-a boy of eight. In both it is probable that the wedge of the radius and ulna had not been inserted far or firmly enough into the distal carpal row. In the second case the patient was too young for this operation, for the small size of the bones made the operation technically more difficult. For this reason, and also because of the additional shortening of the forearm that will occur from premature fusion of the epiphyses, the operation should be deferred, when possible, until bone growth is almost complete. In both cases sound fusion was secured after a further similar operation.

Excessive mobility of the resected lower end of ulna was noted in one case. This caused only slight discomfort.

\section{SUMMARY}

1. A simple and effective method of wrist arthrodesis is described. Originally designed for the correction of flexion deformity of the wrist, it is useful also as a routine method of wrist fusion.

2. The results in nineteen cases are reviewed.

I wish to record my thanks to Mr E. P. Brockman for his help and encouragement in the preparation of this paper, and for permission to review his cases. My thanks are also due to the Photographic Department of Westminster Hospital for assistance with the illustrations.

\section{REFERENCES}

Abbott, Le R. C., SAunders, J. B. De C. M., and Bost, F. C. (1942): Arthrodesis of the Wrist with the Use of Grafts of Cancellous Bone. Journal of Bone and Joint Surgery, 24, 883.

Albee, F. H. (1940): Bone Graft Surgery in Disease, Injury and Deformity. New York and London: D. Appleton-Century Company.

Brittain, H. A. (1952): Architectural Principles in Arthrodesis. Second edition. Edinburgh and London: E. and S. Livingstone Ltd.

Butler, A. A. (1949): Arthrodesis of the Wrist Joint. Graft from Inner Table of the Ilium. American Journal of Surgery, N.S. 78, 625.

Colonna, P. C. (1944): A Method for Fusion of the Wrist. Southern Medical Journal, 37, 195.

DARRACH, W. (1936): In Libre jubilaire offert au docteur Albin Lambotte par ses amis et ses élèves. Brussels: Vromant et Cie.

GILl, A. B. (1949): In Campbell's Operative Orthopedics. Second edition. London: Henry Kimpton.

Higgs, S. L. (1931): “ Hammer-Toe." Postgraduate Medical Journal, 6, 130.

Nissen, K. I. (1951): Symposium on Cerebral Palsy. Proceedings of the Royal Society of Medicine (Section of Orthopaedics), 44, 87.

Ross, W. T. (1950): Arthrodesis of the Wrist Joint. An Analysis of 48 Operations. South African Medical Journal, 24, 755.

Smith-Petersen, M. N. (1940): A New Approach to the Wrist Joint. Journal of Bone and Joint Surgery, 22, 122.

Thомas, D. F. (1950): A Method of Arthrodesis of the Wrist. Lancet, i, 808. 